\title{
Chronic Exposure to Malaria Is Associated with Inhibitory and Activation Markers on Atypical Memory B Cells and Marginal Zone-Like B Cells
}

OPEN ACCESS

Edited by: Deborah K. Dunn-Walters, University of Surrey, United Kingdom

Reviewed by:

Carl De Trez,

Vrije Universiteit Brussel, Belgium

Christopher Sundling, Karolinska Institutet, Sweden

*Correspondence: Carlota Dobaño carlota.dobano@isglobal.org

Specialty section: This article was submitted to B Cell Biology, a section of the journal

Frontiers in Immunology

Received: 28 June 2017

Accepted: 28 July 2017 Published: 21 August 2017

Citation:

Ubillos I, Campo JJ, Requena P,

Ome-Kaius $M$, Hanieh $S$, Rose $H$,

Samol P, Barrios D, Jiménez A, Bardaji A, Mueller I, Menéndez C,

Rogerson S, Moncunill G and Dobaño C (2017) Chronic Exposure to Malaria Is Associated with Inhibitory and Activation Markers on

Atypical Memory B Cells and Marginal Zone-Like B Cells. Front. Immunol. 8:966. doi: 10.3389/fimmu.2017.00966
Itziar Ubillos ${ }^{1}$, Joseph J. Campo ${ }^{1,2}$, Pilar Requena ${ }^{1,3}$, Maria Ome-Kaius $^{4}$, Sarah Hanieh ${ }^{4}$, Honor Rose ${ }^{4}$, Paula Samol ${ }^{4}$, Diana Barrios ${ }^{1}$, Alfons Jiménez ${ }^{1,5}$, Azucena Bardají1, Ivo Mueller ${ }^{4,6}$, Clara Menéndez ${ }^{1}$, Stephen Rogerson ${ }^{7}$, Gemma Moncunill $^{1}$ and Carlota Dobaño ${ }^{1 *}$

'ISGlobal, Barcelona Ctr. Int. Health Res. (CRESIB), Hospital Clinic-Universitat de Barcelona, Barcelona, Spain, ${ }^{2}$ Antigen Discovery Inc., Irvine, CA, United States, ${ }^{3}$ Facultad de Medicina, Universidad de Granada, Granada, Spain, ${ }^{4}$ Papua New Guinea Institute of Medical Research, Madang, Papua New Guinea, ${ }^{5}$ CIBER Epidemiology and Public Health (CIBERESP), Barcelona, Spain, ${ }^{6}$ Walter and Eliza Hall Institute of Medical Research, Parkville, VIC, Australia, ${ }^{7}$ University of Melbourne, Melbourne, VIC, Australia

In persistent infections that are accompanied by chronic immune activation, such as human immunodeficiency virus, hepatitis $C$ virus, and malaria, there is an increased frequency of a phenotypically distinct subset of memory B cells lacking the classic memory marker CD27 and showing a reduced capacity to produce antibodies. However, critical knowledge gaps remain on specific B cell changes and immune adaptation in chronic infections. We hypothesized that expansion of atypical memory B cells (aMBCs) and reduction of activated peripheral marginal zone (MZ)-like B cells in constantly exposed individuals might be accompanied by phenotypic changes that would confer a tolerogenic profile, helping to establish tolerance to infections. To better understand malaria-associated phenotypic abnormalities on B cells, we analyzed peripheral blood mononuclear cells from 55 pregnant women living in a malaria-endemic area of Papua Nueva Guinea and 9 Spanish malaria-naïve individuals using four 11-color flow cytometry panels. We assessed the expression of markers of B cell specificity (IgG and IgM), activation (CD40, CD80, CD86, b220, TACl, and CD150), inhibition (PD1, CD95, and CD71), and migration (CCR3, CXCR3, and CD62I). We found higher frequencies of active and resting aMBC and marked reduction of MZ-like B cells, although changes in absolute cell counts could not be assessed. Highly exposed women had higher PD1+-, CD95+-, CD40+-, $\mathrm{CD} 71^{+-}$, and $\mathrm{CD} 80^{+}$-activated $\mathrm{aMBC}$ frequencies than non-exposed subjects. Malaria exposure increased frequencies of b220 and proapoptotic markers PD1 and CD95, and decreased expression of the activation marker TACI on MZ-like B cells. The increased frequencies of inhibitory and apoptotic markers on activated aMBCs and MZ-like B cells in malaria-exposed adults suggest an immune-homeostatic mechanism for maintaining B cell development and function while simultaneously downregulating hyperreactive B cells. This mechanism would keep the B cell activation threshold high enough to control infection but impaired enough to tolerate it, preventing systemic inflammation.

Keywords: chronic infection, malaria, tolerance, B cells, host-malaria interaction 


\section{INTRODUCTION}

In persistent infections that are accompanied by chronic immune activation, such as human immunodeficiency virus (HIV), hepatitis $\mathrm{C}$ virus (HCV), and malaria, there is constant polyclonal proliferation of antigen-specific B cells. In such cases, homeostatic mechanisms to attenuate chronic antigenic stimulation are necessary to downregulate activation pathways and allow for host tolerance (1-3). The expression "tolerance to malaria infection," in particular, has long been used to explain the fact that in endemic areas Plasmodium infection can occur without malaria disease (4).

It is accepted that in malaria and other chronic infections, sterilizing immunity rarely occurs $(5,6)$ and highly exposed individuals may be carriers of low-density asymptomatic infections $(5,7)$. In addition, there is increasing evidence that chronic Plasmodium parasitemia evades antibody-mediated immunity through dysregulation of $\mathrm{CD}^{+} \mathrm{T}$ cell and $\mathrm{B}$ cell function (5). Exposure-dependent tolerogenic antibody and cell-mediated responses likely avoid full clearance of parasitemia, a phenomenon known also as premunition $(4,7,8)$.

In an effective adaptive immune response, activated B cells undergo a process of class switching recombination, somatic hypermutation (SHM) and affinity selection within the germinal center (GC) to generate long-lived plasma cells (9), memory B cells (MBCs), and protective antibodies (10). The adaptive response to an infection is a tightly controlled process in which inhibitory and proapoptotic receptors such as Fas/CD95 and PD1 (programmed death 1) play an important role in regulating cell survival $(11,12)$. In chronic infections like HIV (13) and malaria (14), and also in autoimmune diseases like rheumatoid arthritis (15) and systemic lupus erythematosus (16), there is upregulation of inhibitory and proapoptotic receptors on B cells coupled with increased frequency of a phenotypically distinct $\mathrm{MBC}$ subset lacking the classic memory marker $\operatorname{CD} 27(2,3,17,18)$ and usually accompanied by an increase of $\mathrm{IgD}^{-} \mathrm{CD} 27^{+}$classical MBC (19-21). Studies of $\mathrm{HIV}$ - and HCV-infected individuals suggested that this CD27$\mathrm{MBC}$ subset may be prone to anergy and/or apoptosis, because they expressed PD1, FCRL4, FcRL5, and CD95 and had a reduced capacity to proliferate $(17,19,22)$. This phenotype gave rise to the denomination of these cells as "exhausted." A phenotypically similar subset called "atypical MBC" (aMBC) has been associated with malaria exposure $(3,18,23-28)$. The role of the anergic and/ or exhausted aMBC in chronic infection is still unknown.

Chronic immune activation also affects circulating $\mathrm{IgM}^{+} \mathrm{CD} 19^{+} \mathrm{CD} 27^{+} \mathrm{MBC}$, which frequency is greatly reduced in HIV (22) and malaria $(18,26,29)$. This B cell subset is similar to marginal zone (MZ)-like B cells, found mainly in secondary lymphoid organs (30) and to a lesser extent in peripheral blood. They link innate and later-occurring adaptive responses and are key to extracellular antigen responses (31). Recent studies highlight the importance of IgM-expressing B cells in generating T-independent rapid and avid response to an infection (32-34). However, their role in chronic infection is unclear.

A common limitation of past studies is the imprecise phenotypical classification of MBC subsets. We have shown that inclusion of IgD in cytometry panels to distinguish between switched
$\left(\operatorname{IgD}^{-}\right)$and unswitched $\left(\operatorname{IgD}^{+}\right) \mathrm{B}$ cells improved the specificity of MBC classification (18). Indeed, our previous work showed that a substantial frequency of $\mathrm{CD} 27^{-} \mathrm{CD} 21^{+}$, presumably naïve $\mathrm{B}$ cells, were actually switched MBC lacking CD27 (resting aMBC) and, conversely, that a substantial proportion of $\mathrm{CD} 27^{-} \mathrm{CD} 21^{-}$, presumably aMBC (aMBC) were actually $\mathrm{IgD}^{+}$and may represent a phenotypically distinct population (18).

Here, we investigated the surface expression of multiple activation-, inhibition- and survival-associated B cell markers in peripheral blood mononuclear cells (PBMCs) from malariaexposed and malaria-naïve donors to characterize cellular phenotypes. We hypothesized that expansion of aMBC with a tolerogenic-like phenotype and reduction of activated peripheral MZ-like B cells in constantly exposed individuals may be a complementary mechanism to downregulate continuously activated $\mathrm{B}$ cells while simultaneously maintaining B cell functions, helping to establish tolerance to the infection $(15,17)$.

\section{MATERIALS AND METHODS}

\section{Study Participants}

The study recruited 55 malaria-exposed pregnant women from the Madang Province in Papua New Guinea (PNG) at their first antenatal clinic visit between 2008 and 2010 (Table 1) and 9 male malaria-naïve donors from Barcelona in Spain. Ten milliliters of heparinized venous blood were collected from volunteers.

\section{Ethical Approval}

Written informed consent was obtained from all study participants. This study was approved by the Medical Research Advisory Committee in PNG (MRAC 08.02) and by the Hospital Clinic of Barcelona Ethics Review Committee (Comitè Ėtic d'Investigació Clínica), Spain.

\section{Isolation of Plasma and PBMC}

Plasma was separated from the cellular fraction of blood within $4 \mathrm{~h}$ of collection by centrifugation at $600 \mathrm{~g}$ for $10 \mathrm{~min}$ at room temperature, aliquoted and stored at $-80^{\circ} \mathrm{C}$. Blood cells were further fractioned in a density gradient medium (Histopaque-1077, Sigma-Aldrich) to obtain PBMCs that were frozen in fetal calf serum and $10 \%$ dimethyl sulfoxide and stored in liquid nitrogen until analysis. PNG samples were shipped to and analyzed at the Barcelona Institute for Global Health (Spain).

\section{Serological Classification of Intensity of Malaria Exposure}

We had previously examined malaria antibody responses in 293 pregnant women from PNG (18). A Luminex microsphere technology-based assay measured IgG responses to Plasmodium falciparum $(P f)$ apical membrane antigen 1 (AMA1), merozoite surface protein 1 (MSP-1 $\left.1_{19}\right)$, and region II of the $175 \mathrm{kDa}$ erythrocyte binding protein (EBA175); as well as Plasmodium vivax $(P v)$ merozoite surface protein 1 (MSP- $1_{19}$ ) and Duffy binding protein, all expressed in Escherichia coli. Antibody levels were expressed as median fluorescence intensity (MFI). For an in-depth B cell analysis, we selected a subset of individuals with diverse antibody 
TABLE 1 | Characteristics of study participants by malaria exposure category.

\begin{tabular}{|c|c|c|c|}
\hline & Non-exposed $(n=9)$ & Low-exposed $(n=26)$ & High-exposed $(n=29)$ \\
\hline $\mathrm{Age}^{\mathrm{a}}$ & $45(31-53)$ & $23.5(19-36)$ & $25(17-38)$ \\
\hline Body mass index & - & $23.6(12.6-29.9)$ & $23.15(18.6-31.6)$ \\
\hline Gestational age (weeks) & NA & $24(18-29)$ & $24(15-31)$ \\
\hline Number of pregnancies ${ }^{a}$ & NA & $2(1-4)$ & $1(1-7)$ \\
\hline Proportion with spontaneous abortion & NA & 3.85 & 3.45 \\
\hline Proportion with moderate anemia ( $<11 \mathrm{mg} / \mathrm{dL})$ & - & 88.46 & 82.76 \\
\hline Proportion with severe anemia (<7 mg/dL) & 0 & 3.85 & 6.9 \\
\hline Proportion with previous malaria & 0 & 23.08 & 13.79 \\
\hline Proportion with fever in the last $24 \mathrm{~h}^{\mathrm{b}}$ & 0 & 7.69 & 3.45 \\
\hline Proportion with ITN use ${ }^{b}$ & NA & 42.86 & 57.14 \\
\hline
\end{tabular}

${ }^{a}$ Data are medians (ranges) and were self-reported.

${ }^{b}$ Self-reported.

ITN, insecticide-treated bed net.

-, data not available

NA, not applicable.

profiles. We classified malaria exposure as high or low according to the magnitude and breadth of antibody levels. We used serology as an indirect measure of both recent and past cumulative exposure to Plasmodium to build a classifier for exposure levels. It is well established in malaria that with cumulative exposure there is an increase in the breadth of response to $P f$ and $P v$ antibody levels (35-40). For magnitude, IgG responses were divided in tertiles and ranked from 1 (low) to 3 (high) for each of the five antigens. For breadth, combined responses ranking from 5 to 9 were classified as low exposure, and those ranking from 10 to 15 as high exposure (Figure S1 in Supplementary Material). We then randomly selected 55 among the 293 malaria-exposed women; 29 were highly exposed and 26 had low exposure.

\section{Phenotyping and Gating Strategy}

Peripheral blood mononuclear cells were thawed, and their viability measured on a Guava ${ }^{\circledR}$ Cytometer using Guava ViaCount Reagent (Millipore, Madrid, Spain). All samples had viabilities $>60 \%$ and were used for the assays. All antibodies and reagents were purchased from BD Biosciences (Madrid, Spain), unless otherwise indicated. For compensation controls, BD Comp Beads were used. Cells and beads were acquired on a BD LSR II Fortessa cytometer.

One million PBMCs per sample were used for B cell staining. Cell suspensions were stained with LIVE/DEAD ${ }^{\circledR}$ Fixable Aqua Dead Cell Stain Kit (Invitrogen, Madrid, Spain), washed and blocked with PBS-BSA $0.05 \%$. After washing, cells were stained in four multiparametric panels having a core panel with the following antibodies: anti-CD3 Horizon v500 (clone UCHT1), anti-CD14 Horizon v500 (clone M5e2), anti-CD16 Horizon v500 (clone 3G8), anti-CD19 PE/CF594 (clone HIB19), anti-IgD allophycocyanin/H7 (clone IA6-2), anti-CD27 allophycocyanin (clone M-T271), anti-surface IgD-APC/H7 (clone IA6-2), antiCD21 FITC (Beckman Coulter, clone BL13), anti-CD38 PerCP (clone HIT2), and anti-CD10 BV421 (BioLegend, clone HI10a). The additional sets of antibodies added to the core panel were as follows: (1) anti-surface IgM PE (clone G20-127), anti-sIgG PE/Cy7 (clone G18-145), rat anti-mouse b220 Alexa Fluor 700 (clone RA3-6B2), and anti-PD1 BV605 (clone EH12.2H7); (2) anti-CD150 PE (clone A12), anti-CD95 PE/Cy7 (clone
DX2), anti-CD40 Alexa Fluor 700 (clone 5C3), and anti-TACI BV605 (BioLegend, clone 1A1); (3) anti-CCR3 PE (clone 5E8), anti-CD71 PE/Cy7 (eBioscience, clone OKT9), anti-CXCR3 Alexa Fluor 700 (clone 1C6), and anti-CD62L BV6054 (clone DREG-56); and (4) anti-CD80 Alexa Fluor 700 (clone L307.4) and anti-CD86 PE/Cy7 (clone 2331).

Fluorescence-minus-one controls were used for gating of positive events (Figure S2 in Supplementary Material). Samples were stained containing all the antibodies of the panel except one marker. These samples were used to determine the negative population for each staining experiment. Figure 1 shows the gating strategy used for this study. Lymphocytes were gated using a time event gate, excluding duplets. Live B cells were displayed according to $\mathrm{CD} 19^{+}$expression and a dump channel containing a viability marker, CD3, CD14, and CD16. Mature viable B cells (VBC) were gated through a Boolean gate containing live B cells, $\mathrm{CD}_{19}{ }^{+}$, and not $\mathrm{CD} 10^{+}$cells. Immature B cells contained $\mathrm{CD} 19^{+}$, $\mathrm{CD} 10^{+}$, and not $\mathrm{CD} 38^{++}$. VBC were further divided into switched $\left(\operatorname{IgD}^{-}\right)$or unswitched $\left(\operatorname{IgD}^{+}\right)$populations, and plasmablast and germinal center cells (PCGC) $\left(\mathrm{IgD}^{-} \mathrm{CD} 38^{++}\right)$(Figure 1). Switched and unswitched populations were displayed according to their expression of CD21 and CD27, and MBC classified as active $\left(\mathrm{CD} 21^{-}\right)$and resting $\left(\mathrm{CD} 21^{+}\right)$. Unswitched $\left(\mathrm{IgD}^{+}\right)$population was divided as naïve $\mathrm{B}$ cells, $\mathrm{MZ}$-like $\mathrm{MBC}$ and active naïve. The switched $\left(\operatorname{IgD}^{-}\right)$population was classified as active classical $\mathrm{MBC}$ (acMBC), resting classical MBC (rcMBC), active atypical MBC (aaMBC), and resting atypical MBC (raMBC) (Figure 1). Every $B$ cell subset was expressed as percentage of total VBC. Shifts in one B cell subset were accompanied by shifts in one or more other B cells subsets. Gating strategy and data analysis was performed on FlowJo software version 9.2 (Tree Star).

\section{Statistical Analysis}

Percentage cell population and frequency of marker expression were compared between three malaria exposure groups, nonexposed, low- and high-exposed individuals, using KruskalWallis test plus Dunn's pairwise post hoc test. Differences between exposed and non-exposed individuals were assessed with the Wilcoxon signed-rank test and adjusted for multiple comparison by the Benjamini and Hochberg method (41). To compare aMBC 


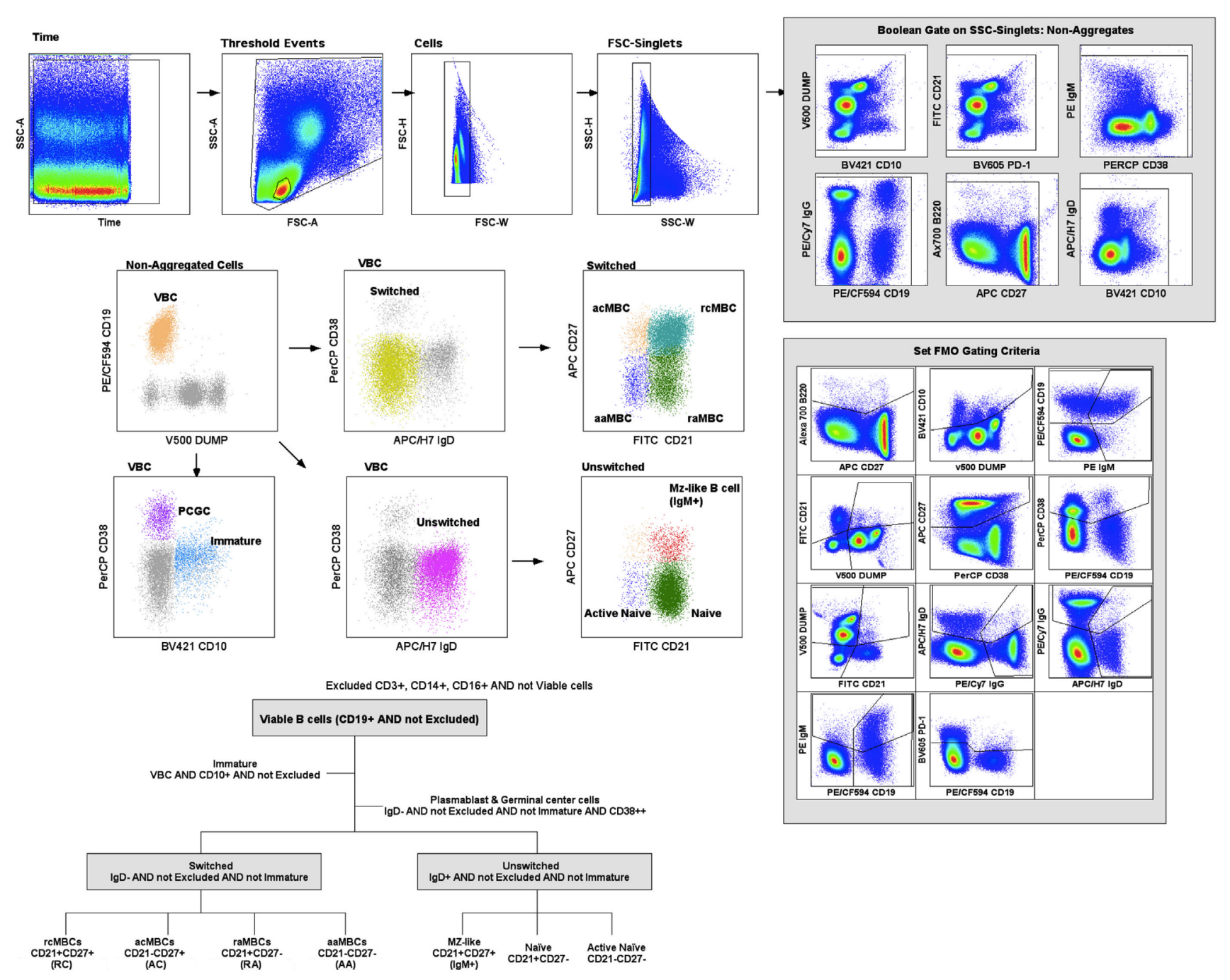

FIGURE 1 | Gating strategy. Cell acquisition was performed on a BD LSR II Fortessa cytometer and data analyzed on Flow Jo (Tree Star). B cell classification was performed based on Boolean gates. Excluded population (CD3+ ${ }^{+} \mathrm{CD} 14^{+} \mathrm{CD} 16^{+}$and viability marker); viable $\mathrm{B}$ cells $(\mathrm{VBC})\left(\mathrm{CD} 19^{+}\right.$AND NOT Excluded); immature

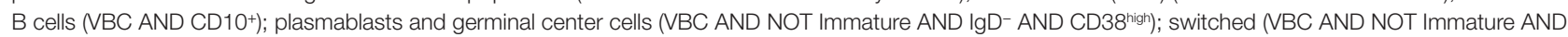
NOT CD38 high AND IgD-); AC indicates active classical memory B cells (MBCs) (Switched AND CD21-CD27+); RC, resting classical MBCs (Switched AND $\mathrm{CD}_{21}{ }^{+} \mathrm{CD} 27^{+}$); $\mathrm{AA}$, active atypical MBCs (Switched AND CD21-CD27-); RA, resting atypical MBCs (Switched AND CD21+CD27-); unswitched (VBC AND NOT Immature AND NOT CD38 high AND IgD+); naïve (Unswitched AND CD21+CD27-); active naïve (Unswitched AND CD21-CD27-) and marginal zone (MZ)-like B cells (Unswitched AND CD21+CD27+ AND lgM+).

and MZ-like B cell frequencies, and marker MFI against the rest of B cell subsets, we used the Friedman test, with Dunn's post hoc test. Analyses and figures were performed using Stata (StataCorp, 2014, Statistical Software, College Station, TX, USA: StataCorp LP) and GraphPad Prism (La Jolla, CA, USA).

\section{RESULTS}

\section{Malaria Exposure Is Associated with Differences in Frequencies of Circulating B Cell Subpopulations}

Baseline population characteristics are described in Table $\mathbf{1 .}$ B cell subsets were characterized (Figure 1) and compared between exposed and non-exposed controls (Table 2), specifically 9 malaria non-exposed, 26 malaria low-exposed, and 29 malaria high-exposed pregnant women. We analyzed the proportions of the following cells: aaMBCs (CD3 ${ }^{-} \mathrm{CD} 14^{-} \mathrm{CD} 16$ ${ }^{-} \mathrm{CD} 19^{+} \mathrm{CD} 10^{-} \mathrm{IgD}^{-} \mathrm{CD} 21^{-} \mathrm{CD} 27^{-}$); raMBCs $\left(\mathrm{CD}^{-} \mathrm{CD} 14^{-} \mathrm{CD} 16\right.$ $\left.{ }^{-} \mathrm{CD} 19^{+} \mathrm{CD} 10^{-} \mathrm{IgD}^{-} \mathrm{CD} 21^{+} \mathrm{CD} 27^{-}\right)$; $\mathrm{acMBCs}^{-\mathrm{CD} 3}{ }^{-} \mathrm{CD} 14^{-} \mathrm{CD} 1$ $\left.6^{-} \mathrm{CD} 19^{+} \mathrm{CD} 10^{-} \mathrm{IgD}^{-} \mathrm{CD} 21^{-} \mathrm{CD} 27^{+}\right)$; $\mathrm{rcMBCs}_{(\mathrm{CD}}{ }^{-} \mathrm{CD} 14^{-} \mathrm{CD}$ $\left.16^{-} \mathrm{CD} 19^{+} \mathrm{CD} 10^{-} \mathrm{IgD}^{-} \mathrm{CD} 21^{+} \mathrm{CD} 27^{+}\right) ; \quad \mathrm{PCGC}\left(\mathrm{CD}^{-} \mathrm{CD} 14^{-} \mathrm{CD}\right.$ $\left.16^{-} \mathrm{CD} 19^{+} \mathrm{CD}_{10} \mathrm{IgD}^{-} \mathrm{CD} 38^{\text {high }}\right)$; naïve $\left(\mathrm{CD} 3^{-} \mathrm{CD} 14^{-} \mathrm{CD} 16^{-} \mathrm{CD}\right.$ $19^{+} \mathrm{CD} 10^{-} \mathrm{IgD}^{+} \mathrm{CD} 21^{+} \mathrm{CD} 27^{-}$); active naïve (CD3 ${ }^{-} \mathrm{CD} 14^{-} \mathrm{CD} 16$ $\left.{ }^{-} \mathrm{CD} 19^{+} \mathrm{CD} 10^{-} \mathrm{IgD}^{+} \mathrm{CD} 21^{-} \mathrm{CD} 27^{-}\right)$; MZ-like B cells (CD3- ${ }^{-} \mathrm{CD} 1$ $4^{-} \mathrm{CD} 16^{-} \mathrm{CD} 19^{+} \mathrm{CD} 10^{-} \mathrm{IgD}^{+} \mathrm{CD} 21^{+} \mathrm{CD} 27^{+} \mathrm{IgM}^{+}$); and immature $\mathrm{B}$ cells $\left(\mathrm{CD} 3^{-} \mathrm{CD} 14^{-} \mathrm{CD} 16^{-} \mathrm{CD} 19^{+} \mathrm{CD} 10^{+}\right)$. B cell classification was performed based on previous phenotyping experiments (19, 
TABLE 2 | B cell subpopulation percentages calculated as proportion of total viable B cells in malaria non-exposed $(n=9)$ and malaria-exposed $(n=55)$ individuals and $95 \%$ confidence interval.

\begin{tabular}{lccccc}
\hline B cell subsets & \multicolumn{2}{c}{ Not exposed } & \multicolumn{2}{c}{ Exposed } & \multirow{2}{*}{$\boldsymbol{p}^{*}$} \\
\cline { 2 - 5 } & \% & $\mathbf{9 5 \%} \mathbf{~ C l}$ & $\%$ & $\mathbf{9 5 \%} \mathbf{~ C l}$ & \\
\hline Naïve & 39.66 & $31.7-47.6$ & 31.67 & $28.2-35.2$ & 0.11 \\
Active naïve & 1.78 & $0.0-3.5$ & 3.25 & $2.7-3.8$ & 0.005 \\
MZ-like B cells & 12.05 & $6.6-17.5$ & 2.76 & $2.3-3.3$ & $<0.001$ \\
Plasmablast and & 1.21 & $0.6-1.8$ & 8.98 & $7.2-10.7$ & 0.023 \\
germinal center & & & & & \\
Immature & 7.8 & $5.3-10.3$ & 4.04 & $3.1-5.0$ & 0.962 \\
Active atypical MBCs & 1.54 & $0.2-2.9$ & 9.08 & $7-11.2$ & $<0.001$ \\
Resting atypical MBCs & 8.42 & $5.4-11.5$ & 15.75 & $12.7-17.8$ & 0.002 \\
Active classical MBCs & 1.48 & $0.9-2.1$ & 2.8 & $2.3-3.3$ & 0.041 \\
Resting classical MBCs & 20.27 & $16.5-24.1$ & 17.72 & $15.6-19.8$ & 0.21 \\
\hline
\end{tabular}

${ }^{*} p$-Values adjusted for multiple testing by Benjamini and Hochberg method.

MZ-like B cells, marginal zone-like B cells; MBC, memory B cell.

42). The classification of plasmablast and GC (or GC-like) cells follows the Bm1-5 gating strategy using $\operatorname{IgD}$ and CD38 (42); it is worth noting that the PCGC subpopulation represents a small fraction of circulating B cells, and that some pre-GC and recent GC B cells may be caught in the peripheral blood. Eight individuals had a Pf infection, measured by PCR, three individuals in the high-exposure and five individuals in the low-exposure groups. We found no significant differences in B cell subset frequencies and proportions of marker expression in infected versus noninfected individuals, as shown before for aMBC or MZ-like B cells in this cohort (18) and as reported by others $(3,43)$ (Table S1 in Supplementary Material). Thus, individuals with infection were included in the overall analysis. As previously shown in the literature, frequencies of peripheral blood aaMBC, raMBC, acMBC, and PCGC were increased in exposed individuals (Table 2). We also confirmed the strong decline in the proportion of circulating MZ-like B cells with malaria exposure. Overall, we did not find statistically significant differences in the B cell subset proportions between high- and low-exposed individuals. However, for aaMBC, raMBCs, and acMBC, the differences were greater when non-exposed were compared to individuals with high exposure than to those with low exposure (Figure 2). Based on these results, we focused our study on switched (atypical and classical) MBC and MZ-like B cells.

\section{Malaria Exposure Alters Atypical and Classical MBC Phenotypes}

We compared frequencies of B cell subsets expressing markers of activation and co-stimulation (IgG, IgM, b220, CD40, CD150, CD80, and CD86), inhibition (PD1, CD95, and TACI) and migration (CD62L, CXCR3, CCR3, and CD71) between malaria-exposed and non-exposed individuals (Table 3; Table S2 in Supplementary Material) and between different categories of exposure and non-exposed (Figure 3). Non-statistically significant differences were detected between low-exposed and high-exposed pregnant women in $\mathrm{IgG}^{+}$aaMBC or $\mathrm{IgG}^{+}$acMBC frequencies, but $\mathrm{IgG}^{+}$raMBC and $\mathrm{IgG}^{+}$rcMBC expression was increased in highly exposed individuals (Figure 3A). $\operatorname{IgM}^{+}$aaMBC and $\mathrm{IgM}^{+}$raMBCs were not affected by exposure. However, IgM-expressing acMBC and $\mathrm{rcMBC}$ had a marked reduction in frequency with increased malaria exposure (Figure 3B), as seen in previous studies on HIV-infected individuals (2).

$\mathrm{PD} 1$, a marker of $\mathrm{T}$ cell activation and exhaustion, plays important roles in negative regulation of $\mathrm{T}$ cell responses and maintenance of peripheral tolerance in malaria infection (25). Frequencies of $\mathrm{PD}^{+}$aaMBCS were significantly increased in exposed individuals (Table 3; Figure S3 in Supplementary Material), with higher frequencies of $\mathrm{PD}^{+}$aaMBCS in low and high-exposed compared to non-exposed volunteers (Figure 4A). No differences in the expression of this marker were observed for the other switched B cell subsets. Increased expression of Fas/CD95 by circulating B cells has been related to MBC activation (16), described in chronic antigen exposure $(15,16,19)$ and associated with induction of apoptosis (12). Frequencies of $\mathrm{CD} 95^{+}$-expressing aaMBCs, raMBCs, acMBCs, and rcMBCs were increased in exposed individuals compared to non-exposed (Table 3; Table S2 in Supplementary Material). However, no statistically significant differences were found between high and low malaria-exposed groups (Figure 4; Figure S3 in Supplementary Material).

$\mathrm{B}$ cell activation by a T-dependent signaling pathway involves the interaction with co-stimulatory molecules: CD28 on T cells, CD80 and CD86 on B cells. CD80 also binds to PD1 ligand (PD1L) providing a negative signal for proliferation and IgG secretion of normal B cells. In contrast, CD86 enhances B cell activity (44). Interactions of PD1L with its two ligands, PD1 and CD80, on $\mathrm{T}$ cells play a key role in controlling $\mathrm{T}$ cell activation, proliferation, anergy and apoptosis (45).

Triggering of CD80 specifically inhibits B cell proliferation, whereas CD86 enhances B cell activity (53). Malaria-exposed women had increased frequencies of $\mathrm{CD} 80^{+}$active and raMBCs and $\mathrm{CD} 86^{+}$resting atypical and classical MBC compared to nonexposed (Table 3; Table S2 in Supplementary Material).

CD40 signaling is required for GC formation but, paradoxically, strong CD40 signaling causes B cells to become GC-independent MBCs. It also provides short-term rescue signals to avoid CD95induced death by upregulating antiapoptotic proteins $(32,46)$. We observed higher frequencies of $\mathrm{CD} 40^{+}$aaMBCs and CD $40^{+}$ acMBCs in malaria-exposed compared to non-exposed individuals, with a tendency of increased frequencies with higher exposure. No effect of malaria exposure was observed on $\mathrm{CD} 40^{+}$resting classical or atypical MBCs (Figure 4; Figure S4 in Supplementary Material).

Transferrin receptor (CD71) is a cell surface molecule that regulates uptake of iron-bound transferrin by receptor-mediated endocytosis, is expressed in dividing cells and is a marker of B cell endocytosis $(18,47,48-50)$. Highly exposed individuals had increased frequencies of $\mathrm{CD}_{71} 1^{+}$aaMBCs compared to nonexposed individuals (Figure 4A), but no other association with malaria exposure was found for CD71 expression in the remaining switched B cell subsets (Table S2 in Supplementary Material).

B cells downregulate expression of b220 (a glycoform of CD45R) after or during migration from follicular mantle zones to GCs and prior to reentering circulation (51). We found no statistically significant differences in the frequency of b220 ${ }^{+}$cells 

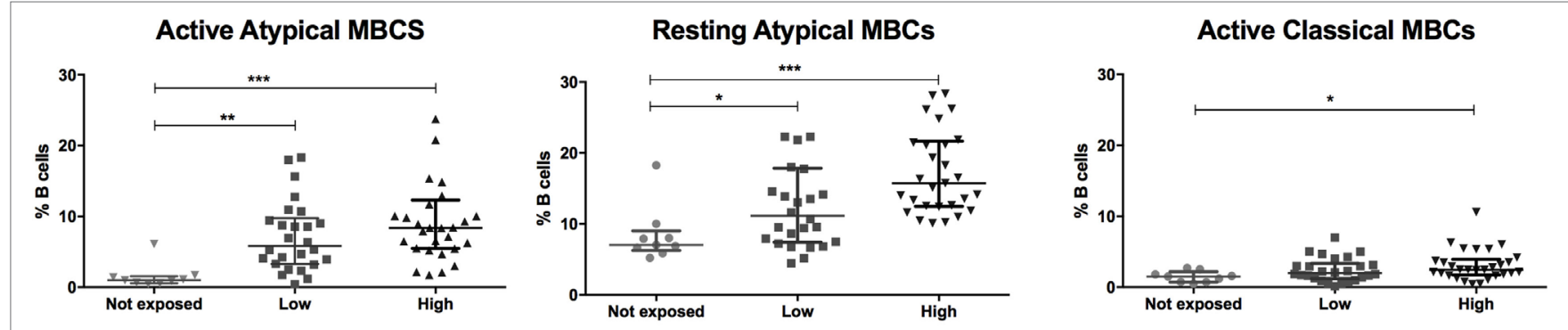

Plasmablast \& Germinal Center cells

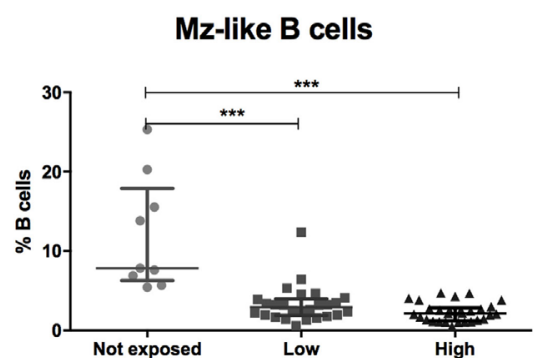

FIGURE 2 | Malaria exposure is associated with changes in the frequencies of different B cell subsets. Beeswarm plots show B cell subset frequencies in the groups categorized by malaria exposure. No exposure (Not exposed; $n=9$ ), low exposure (Low; $n=26$ ), and high exposure (High; $n=29$ ). Lines and whiskers represent median and interquartile range, respectively. Differences were assessed with Kruskal-Wallis test plus Dunn's post hoc test comparing each exposure category $\left({ }^{*} p \leq 0.05,{ }^{* *} p \leq 0.01,{ }^{* * *} p \leq 0.001\right)$.

TABLE 3 | Phenotypic marker frequencies in malaria-exposed and non-exposed individuals.

\begin{tabular}{|c|c|c|c|c|c|c|c|c|c|}
\hline & \multicolumn{3}{|c|}{ aaMBC, mean (95\% Cl) } & \multicolumn{3}{|c|}{ raMBC, mean $(95 \% \mathrm{Cl})$} & \multicolumn{3}{|c|}{ MZ-like B cells, mean $(95 \% \mathrm{Cl})$} \\
\hline $\lg G$ & $42.08(23.3-60.8)$ & $57.6(51.7-63.4)$ & 0.164 & $25.26(14.8-35.6)$ & $47.8(42.5-53)$ & 0.015 & $1.69(0.4-2.9)$ & $4.09(2.4-5.7)$ & 0.224 \\
\hline b220 & $34.08(13.4-54.7)$ & $14.93(10.6-19.2)$ & 0.149 & $23.54(9.9-37.1)$ & $16.07(11.8-20.2)$ & 0.373 & $8.49(3.7-13.2)$ & $14.49(12.2-16.7)$ & 0.7 \\
\hline PD1 & $5.64(1.2-10)$ & $19.74(15.6-23.8)$ & 0.027 & $0.49(0.2-0.7)$ & $1.69(1-2.3)$ & 0.155 & $1.07(0.1-2.1)$ & $4.27(2.3-6.2)$ & 0.052 \\
\hline CD40 & $49.98(31.6-68.3)$ & $71.63(65.6-77.6)$ & 0.065 & $90.01(80-99.9)$ & $95.39(93.8-96.8)$ & 0.373 & $82.63(71.1-94.1)$ & $88.7(86.2-91.3)$ & 0.299 \\
\hline CD150 & $17.04(6.2-27.8)$ & $14.62(11.1-18)$ & 0.702 & $10.31(-1.6$ to 22.3$)$ & $13.47(9.9-16.9)$ & 0.163 & $22.46(-2.4$ to 47.3$)$ & $36.49(28.5-44.4)$ & 0.109 \\
\hline CCR3 & $18.98(5.1-32.8)$ & $17.17(11.4-22.8)$ & 0.695 & $12.34(-10.7$ to 35.4$)$ & $14.18(7.2-21.1)$ & 0.372 & $13.11(-8.5$ to 34.8$)$ & $14.24(7.6-20.8)$ & 0.837 \\
\hline CXCR3 & $1.23(0-2.5)$ & $2.95(1.6-4.2)$ & 0.162 & $2.8(0.8-4.8)$ & $4.42(1.4-7.4)$ & 0.88 & $1.99(0.4-3.5)$ & $4.27(1.7-6.7)$ & 0.403 \\
\hline CD71 & $27.75(14.2-41.2)$ & $47.48(41.4-53.5)$ & 0.056 & $22.96(1.9-43.9)$ & $35.01(28.5-41.5)$ & 0.127 & 10.79 (-6 to 27.6$)$ & $15.06(9.6-20.5)$ & 0.164 \\
\hline CD62L & $14.87(10.6-19.1)$ & $15.43(12.1-18.6)$ & 0.62 & $23.16(13.4-32.8)$ & $31.65(26.7-36.5)$ & 0.332 & $29.8(15.9-43.7)$ & $31.87(26.8-36.8)$ & 0.855 \\
\hline CD80 & $3.91(1.4-6.3)$ & $9.29(7-11.4)$ & 0.043 & $4.81(2.2-7.3)$ & $10.19(8.3-12)$ & 0.027 & $1.35(0.8-1.8)$ & $2.85(2.2-3.4)$ & 0.128 \\
\hline
\end{tabular}

Percentages of $B$ cell subsets expressing specific marker were calculated as proportions of total $B$ cell subset.

${ }^{*} p$-Values adjusted for multiple testing by Benjamini and Hochberg method, comparing malaria-exposed and non-exposed individuals.

$N A$, not applicable; $M B C$, memory B cell; $M Z$, marginal zone; aaMBC, active atypical $M B C$; raMBC, resting atypical $M B C$.

aaMBCs (CD19+CD10-lgD-CD21-CD27-), raMBCs (CD19+CD10-lgD-CD21+CD27-), and MZ-like B cells (CD19+CD10-lgD+CD21+CD27+lgM+').

between exposed and non-exposed individuals for any of the B cell subsets (Table S2 in Supplementary Material; Table 3).

\section{Malaria Exposure Is Associated with Upregulation of Inhibitory Markers on Peripheral MZ-Like and Active Naïve B Cells}

To investigate changes that drive the intense depletion of circulating MZ-like B cells in individuals chronically exposed to malaria, we analyzed the surface expression of activation, inhibition, and migration markers on peripheral MZ-like B cells across exposure categories. $\mathrm{PD} 1^{+}$MZ-like B cells were more frequent in individuals with the highest malaria exposure level compared to non-exposed (Figure 5A). We also found increased proportions of $\mathrm{IgG}^{+}, \mathrm{CD}^{+} 5^{+}$, and b220+ $\mathrm{MZ}$-like B cells with malaria exposure, although differences did not reach statistical significance (Figure 5A). The trans-membrane activator calcium modulator and cyclophilin ligand interactor (TACI), a B cell activation factor $(\mathrm{BAFF})$ receptor, promotes the differentiation of $\mathrm{B}$ cells into 


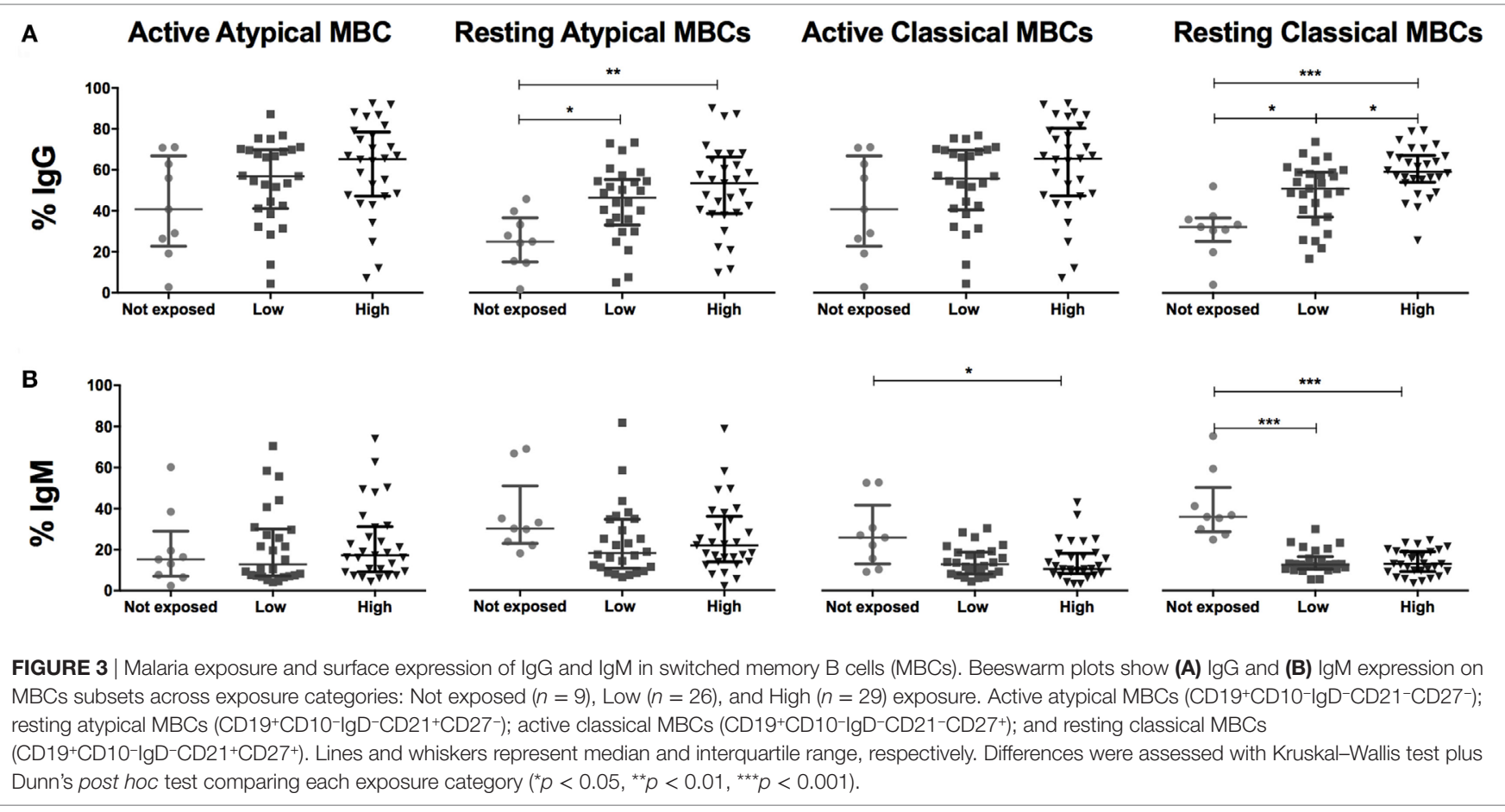

plasma cells $(41,42)$. We found decreased proportions of TACI ${ }^{+}$ MZ-like B cells in the highly exposed group compared to the nonexposed one (Figure 5A). In summary, malaria exposure reduced circulating MZ-like B cells, increased expression of b220 and proapoptotic markers PD1 and CD95, and decreased expression of the activation marker TACI. Finally, we also found increased frequencies of CD95 and PD1 expression on active naïve B cells (Figure 5B; Table S2 in Supplementary Material).

\section{aaMBCs Express More Inhibitory Markers Compared to Other B Cell Subsets in Malaria-Exposed Individuals}

We described the phenotypic profile of atypical aMBC and other B cell subsets in malaria-exposed women to assess the effect of chronic exposure. For this objective, we included only malaria-exposed individuals in the analysis. As expected, aaMBC and acMBCs had the highest frequencies of $\operatorname{IgG}^{+}$cells within the switched compartment, and IgM was highly expressed in unswitched B cells subsets (Table 3; Table S2 in Supplementary Material). PD1 was expressed on aaMBCs more than in any other B cell subset, both expressed as percentage of positive cells and MFI values (Figure 6). Frequencies and levels of expression of CD95 were similar between aaMBCs, acMBCs, rcMBS, and PCGC subsets, and higher compared to the rest of the subsets (Table 3; Figure 6A). PCGC had the highest percentage of $\mathrm{CD}_{7}{ }^{+}$cells, followed by the other switched MBC (Table S3 in Supplementary Material; Figure 6A), but the highest magnitude of CD71 expression was found on aaMBCs (Figure 6B). aaMBCs and raMBCs had the highest CD80 expression, whereas the unswitched, MZ-like, naïve, and active naïve B cells had the lowest frequency (Table 3; Table S2 in Supplementary Material).
In addition, as recent studies on the origin of aaMBCs suggested that aaMBCs and acMBCs may come from the same precursor $(14,57)$, we analyzed paired expression of our markers in aaMBC and acMBC to assess hypothetical differences in marker expression. We found that aaMBC had higher frequencies of $\mathrm{PD}^{+}, \mathrm{b} 220^{+}, \mathrm{IgM}^{+}$, and $\mathrm{CD} 86^{+}$cells and lower proportions of $\mathrm{CD}_{2} \mathrm{~L}^{+}$cells than acMBC (Figure S5 in Supplementary Material).

Finally, we found that MZ-like B cells had increased expression of TACI. TACI is expressed mostly on MZ-like B cells, CD27 ${ }^{+}$ MBCs, and plasma cells $(31,52)$. Here, TACI was mainly present on MZ-like B cells and rcMBCs and raMBCs, all expressing CD21 (Table 3; Table S2 in Supplementary Material; Figure 7). In addition, MZ-like $\mathrm{B}$ cells had lower frequencies of b220 ${ }^{+}$cells than the rest of the unswitched B cell subsets (Figure 7).

\section{DISCUSSION}

Our findings confirm that the circulating B cell compartment of pregnant women with frequent Plasmodium antigen exposure is dramatically altered, likely because of modifications in the frequency and phenotype of different B cell subsets due to chronic immune activation. Malaria exposure is associated with an increase of aaMBC and a decrease of MZ-like B cell frequencies in peripheral blood, as reported in $\operatorname{HIV}(51,58)$ and previous malaria $(20,26)$ studies.

Individuals highly exposed to malaria had more $\mathrm{PD}^{+}, \mathrm{CD}^{+} 5^{+}$, $\mathrm{CD}^{+} 0^{+}, \mathrm{CD} 1^{+}$, and $\mathrm{CD} 40^{+}$aaMBC than malaria non-exposed individuals. Within the malaria-exposed, expression (\% and/or MFI) of PD1 and CD95 was highest in aaMBCs, consistent with the higher expression of $P C P D 1$, the signaling regulator of PD1, shown in aaMBCs (28). Individuals chronically infected with 

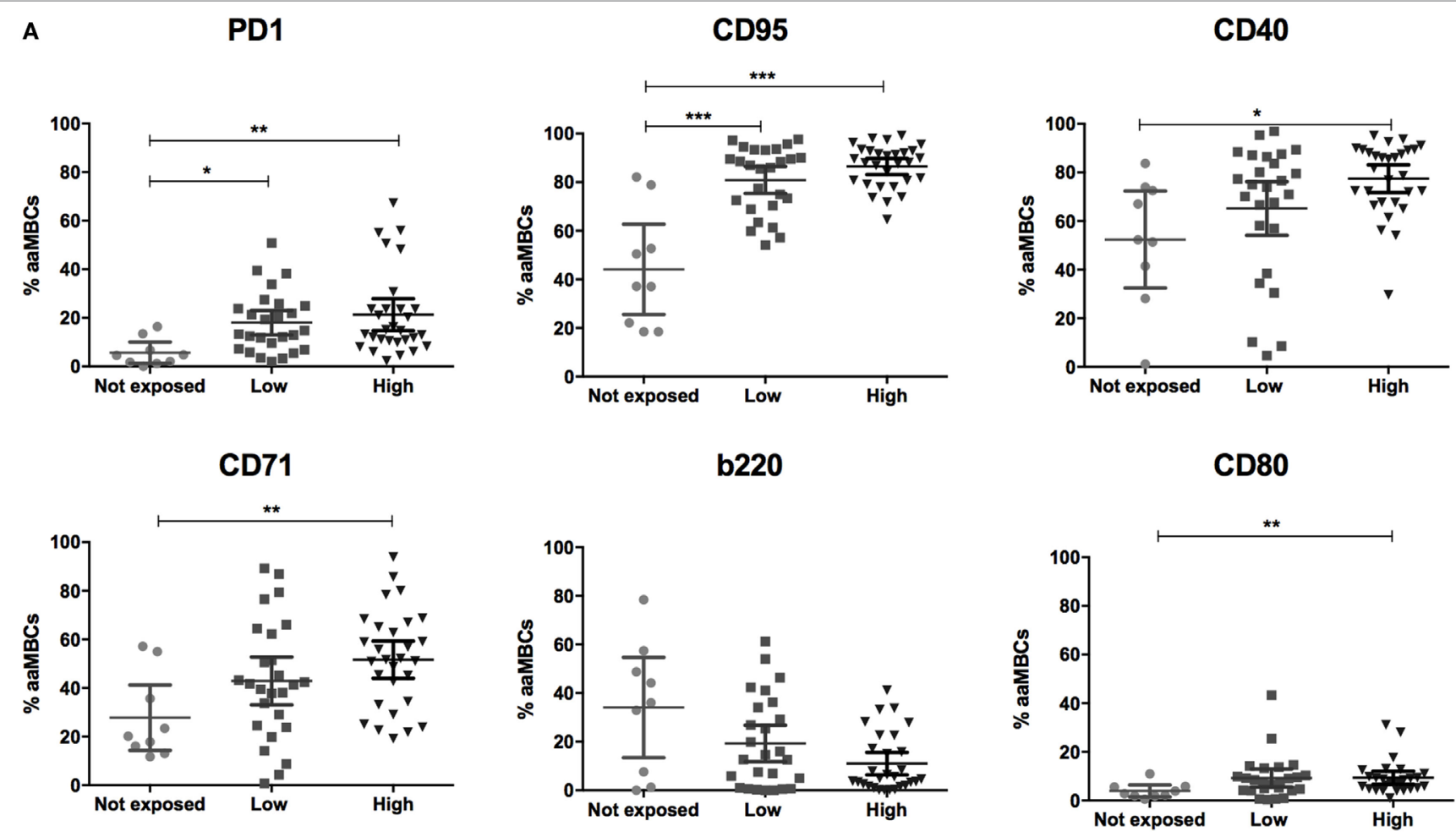

B

PD1

CD95

CD40
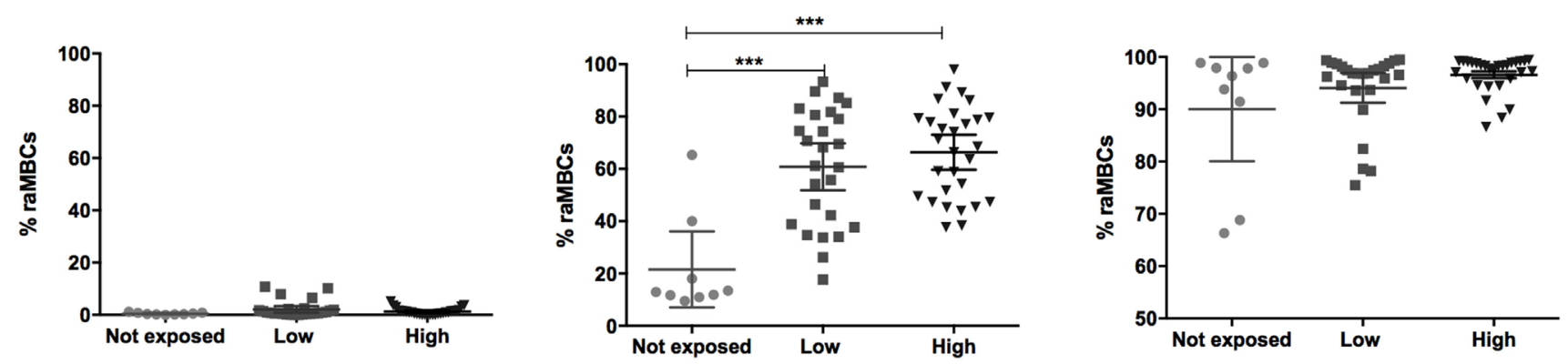

CD71

b220
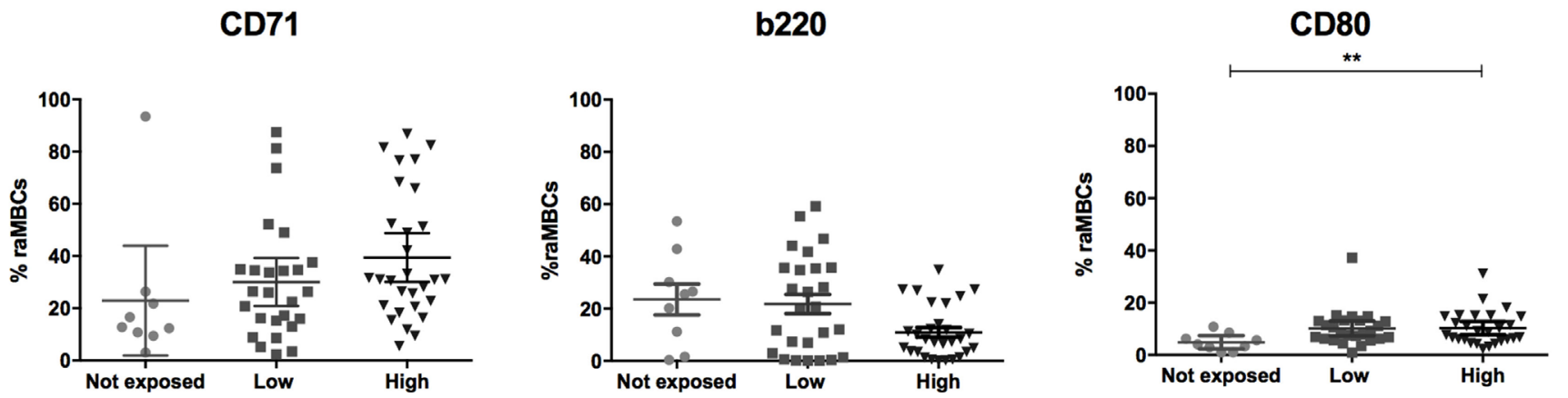

FIGURE 4 | Malaria exposure is associated with changes in atypical memory B cells (MBCs) phenotypes. Graphs show the frequencies of PD1, CD95, CD40, CD71, and b220-expressing (A) active atypical MBCs (aaMBCs, CD19+CD10-lgD-CD2-CD27-) and (B) resting atypical MBCs ( $\left(\mathrm{rCMBCs}^{-}\right.$,

CD19+CD10-IgD-CD21+CD27-) among malaria exposure categories: Not exposed $(n=9)$, Low $(n=26)$, and High $(n=29)$ exposure. Beeswarm plots with lines representing median and interquartile range, respectively. Differences were assessed with Kruskal-Wallis test plus Dunn's post hoc test comparing each exposure category $\left({ }^{\star} p<0.05,{ }^{\star \star} p<0.01,{ }^{\star \star \star} p<0.001\right)$. 

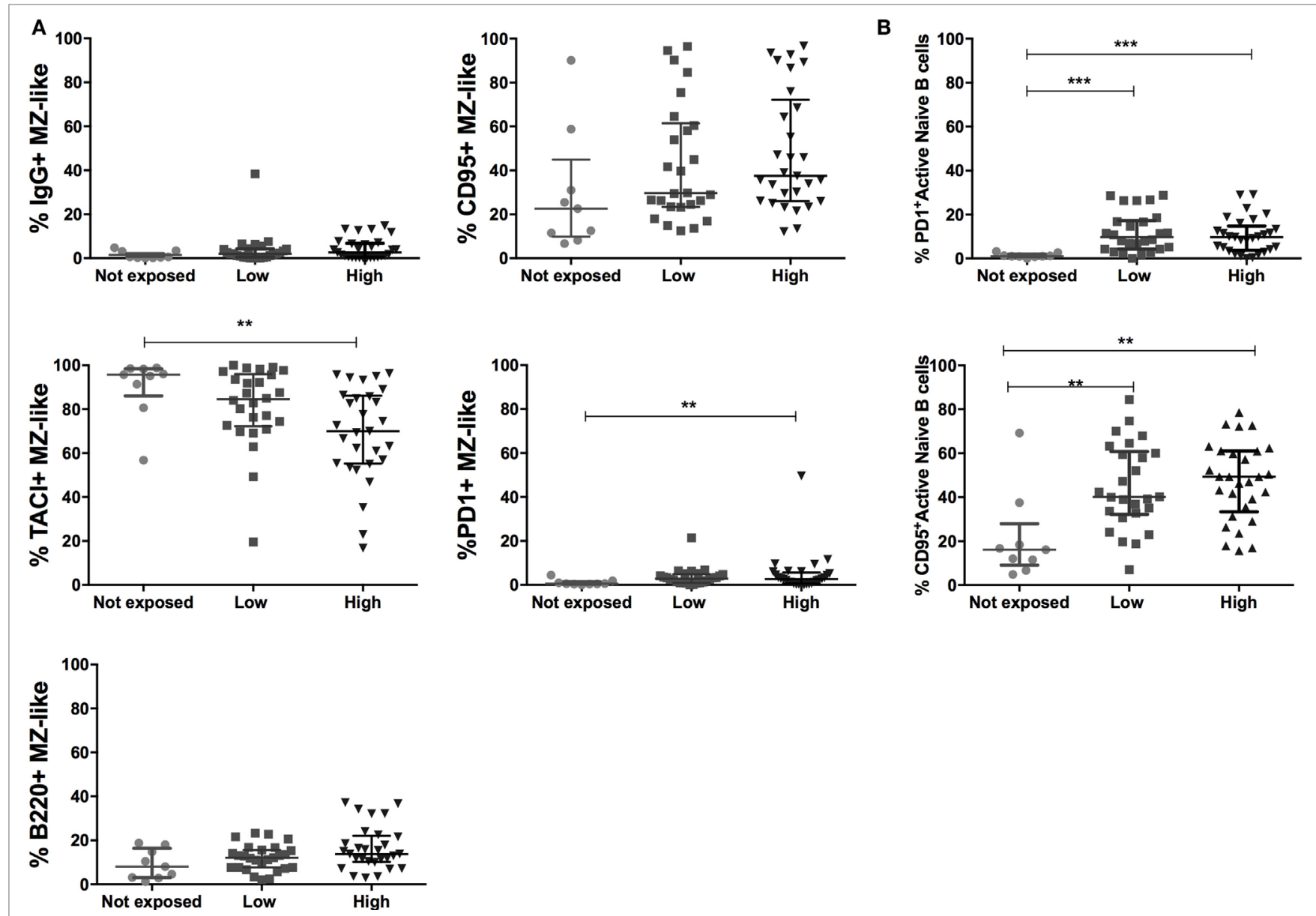

FIGURE 5 | Malaria exposure and upregulation in inhibitory markers on marginal zone (MZ)-like and active naïve B cells. (A) MZ-like B cells $\left(\mathrm{CD} 10^{-} \operatorname{lgD}{ }^{+} \mathrm{CD} 21^{+} \mathrm{CD} 27^{+} \operatorname{lgM}{ }^{+}\right)$expressing $\operatorname{lgG}, \mathrm{TACl}, \mathrm{b} 220, \mathrm{CD} 95$, and PD1 and (B) active naïve B cell expressing CD95 and PD1 in Non- $(n=9)$, Low- $(n=26)$, and High-exposed $(n=29)$ individuals. Beeswarm plots with lines representing median and interquartile range, respectively. Differences were assessed with Kruskal-Wallis test plus Dunn's post hoc test comparing each exposure category $\left({ }^{*} p<0.05,{ }^{* \star} p<0.01,{ }^{* \star \star} p<0.001\right)$.

Pf, HIV, HBV, or HCV, have higher PD1 expression on T cells, a marker of both activation and immune suppression $(2,11,25)$, and its blockade is also a target for immune therapies in HCV and melanomas $(45,59,61,63)$. To the best of our knowledge, this is the first time that increased PD1 expression has been described on $\mathrm{B}$ cell subsets in the context of chronic malaria exposure. In addition, increased expression of Fas/CD95 by aaMBC-like phenotypes has previously been found in HIV infection (13), rheumatoid arthritis disease (15) and active systemic lupus erythematosus (16). Malaria-related increase in CD95 and PD1 expression on aaMBCs could be responsible for their increased susceptibility to cell death (64). However, this seems unlikely, as aMBCs are found at high frequencies in malaria-exposed populations $(3,14,21,25,60)$.

Increased CD40 expression associated to malaria exposure might favor aaMBC survival, as strong CD40L stimulus of GC cells has resulted in production of antiapoptotic proteins, providing survival signals rescuing the GC B cells from CD95-induced death (46). PD1 and CD95 expression in constantly activated
B cells may be involved in mechanisms of immune inhibition rather than apoptosis (54) helping to establish tolerance to chronic infection and in agreement with previously detected higher expression of B cell survival genes in aaMBCs (28).

We also observed that malaria-exposed individuals had higher frequencies of $\mathrm{CD} 80^{+}$raMBC and $\mathrm{CD} 80^{+}$aaMBC than the nonexposed individuals but only raMBC had higher proportions of $\mathrm{CD}^{2} 6^{+}$cells in the exposed group. Triggering of CD80 inhibits proliferation by upregulating the expression of proapoptotic molecules and downregulating levels of antiapoptotic molecules, whereas CD86 boost B cell activity; both markers have been involved in apoptosis via the CD95/CD95L pathway $(37,55,62)$. CD80 might interact with PD1L in a reverse signaling pathway that promotes B cell anergy, as seen on T cells (56). The mechanisms establishing the balance between immune inhibition and cell death are complex, but both mechanisms seem to play a role in tolerogenic responses to infection (54).

The proportion of $\mathrm{IgG}^{+}$aaMBCs did not change with malaria exposure, whereas $\mathrm{IgG}^{+}$raMBC and $\mathrm{IgG}^{+}$rcMBC proportions 

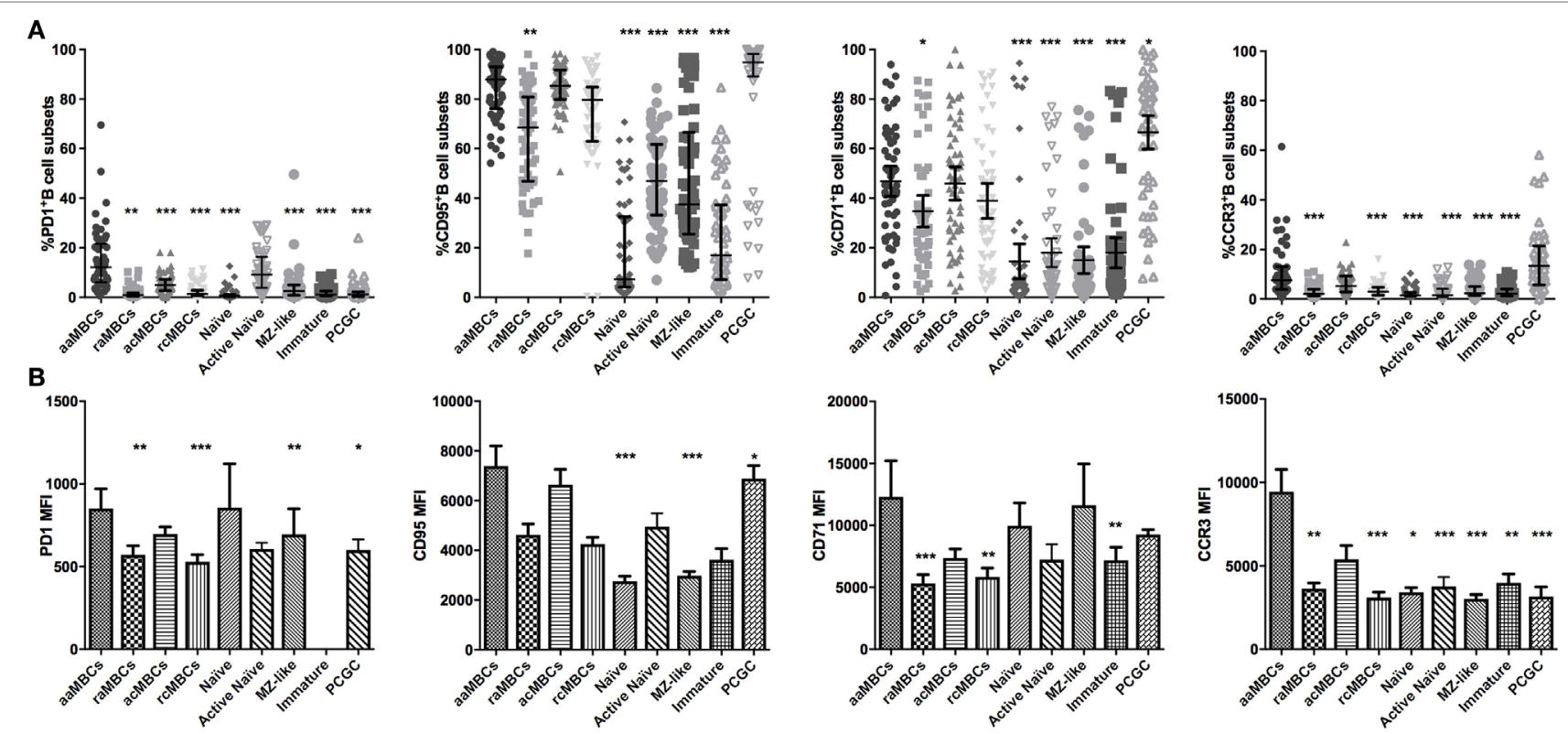

FIGURE 6 | Expression of PD1, CD95, CD71, and CCR3 in B cell subpopulations in malaria-exposed individuals. (A) Frequencies (\%) expressed median and interquartile range, respectively, and (B) magnitude of expression, each bar represents the SE about the mean. Differences were assessed with the Friedman test plus Dunn's post hoc test, comparing active atypical memory B cells (aaMBCs) versus every other B cell subset $\left(N=55\right.$; ${ }^{*} p<0.05$, ${ }^{* *} p<0.01$, $\left.{ }^{* * *} p<0.001\right)$. MBC, memory B cell; raMBC, resting atypical MBC; acMBC, active classical MBC; rcMBC, resting classical MBC; PCGC, plasmablast and germinal center cells.
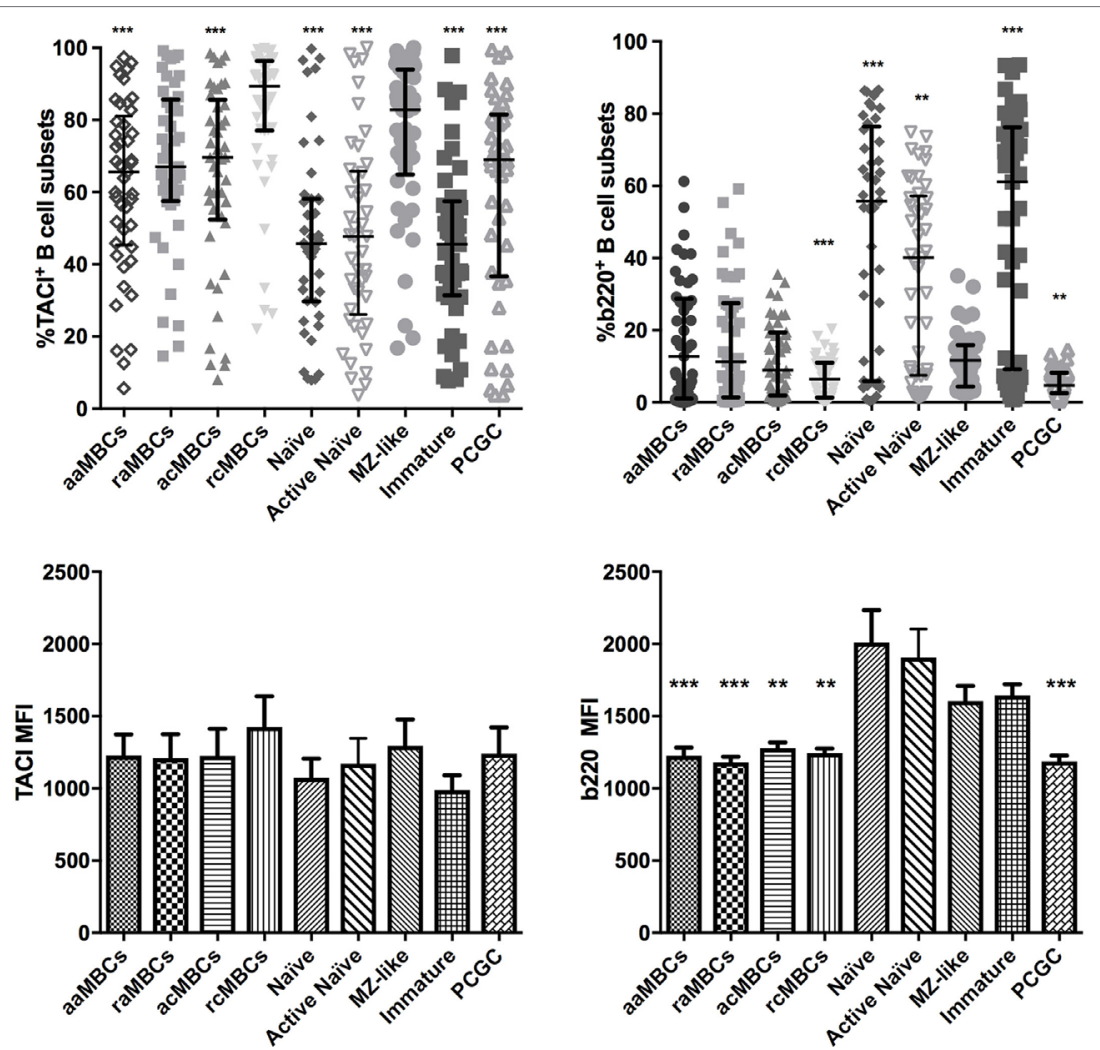

FIGURE 7 | Distribution of expression of TACl and b220 B cell subpopulations in malaria-exposed individuals. Frequencies (\%) expressed median and interquartile range of TACl-expressing B cells and b220-expressing B cells. Differences were assessed with the Friedman test plus Dunn's post hoc test, comparing marginal zone (MZ)-like B cells versus every other B cell subset $\left({ }^{*} p<0.05,{ }^{* *} p<0.01,{ }^{* * *} p<0.001\right)$. MBC, memory B cell; aaMBC, active atypical MBC; raMBC, resting atypical MBC; acMBC, active classical MBC; rcMBC, resting classical MBC; PCGC, plasmablast and germinal center cells. 
increased with exposure levels. Chronic antigen exposure can cause downregulation of IgG surface levels after B cell receptor internalization via endocytosis in favor of transition to secretory Ig in activated B cells (9). We analyzed the expression of CD71 as a marker of B cell endocytosis (18) and observed that CD71 ${ }^{+}$ aaMBCs were more frequent in exposed individuals, suggesting that aaMBCs recognize and internalize fewer antigens than other switched B cell subsets (18). The correlation between the number of cell surface CD71 molecules and the rate of cell proliferation is well known (47), as seen in numerous oncogenic cells $(31,39$, 47-50). The increased frequencies of aaMBCs expressing CD71 in malaria-exposed pregnant women suggests that aaMBCs may proliferate at a higher rate in malaria-exposed individuals and is consistent with the overall higher frequencies of aaMBC in these individuals. Whether aaMBCs have increased capacity to proliferate or the higher CD71 expression on these cells need further studies.

Peripheral MZ-like B cells have been associated with T-independent immune responses and can undergo SHM $(30,31,52)$. We confirmed decrease in circulating MZ-like B cell frequency $(18,26)$ and have shown, for the first time, $\mathrm{TACI}^{+}$ MZ-like B cell frequency reduction and higher CD95 expression with increasing malaria exposure. TACI deficiency impairs antibody responses to polysaccharide antigens, which may explain the increased vulnerability to infection with encapsulated organisms associated with malaria $(29,65)$. Also, the observed exposure-dependent reduced frequencies of $\mathrm{TACI}^{+} \mathrm{MZ}$-like $\mathrm{B}$ cells may jeopardize the production of long-lived antibody secreting cells (ASCs) at the expense of short-lived ASCs, as seen in malaria-exposed populations $(66,67)$ and is consistent with hypogammaglobulinemia, associated with deficiencies in TACI gene expression seen in common variable immunodeficiency disease (65). Also, highly exposed individuals have an increased frequency of $\mathrm{IgG}^{+} \mathrm{MZ}$-like B cells, although the difference was not statistically significant. This finding suggests that once TACI is activated after TLR-4 stimulation, there might be rapid T-independent antibody responses from peripheral MZ-like $B$ cells that constitute an efficient first line of defense. Then, TACI-expressing peripheral MZ-like B cells upregulate CD95 and CD95L, and suppress inhibitors of CD95, which could result in apoptosis, preventing long-lasting activation (52). To the best of our knowledge, this is the first time that dual expression of CD95 and IgG on MZ-like B cells has been described in individuals with chronic antigen exposure. Although we propose that activated peripheral MZ-like B cells activate cell death (52), which explains part of the lower proportion of circulating MZ-like B cells in malaria exposed, we cannot rule out that part of this may be because active MZ-like B cells could be located in lymphoid organs (31). Also, non-antigen-specific cells, like active naïve B cells, have increased expression of CD95 and PD1 with malaria exposure, suggesting that chronic infections may alter the phenotype, but this finding requires future studies. We did not find differential expression of migration markers in B cell subsets associated to malaria exposure.

The study of the origin of atypical MBCs has been controversial, a study in malaria-exposed children reported that aMBCs and cMBCs may share similar rates of SHM, suggesting a shared origin (14) whereas other study suggested a different origin (68). We found differences in the expression of PD1, b220, CD86, CD62L, IgM, and IgG between acMBC and aaMBCs and we can speculate that acMBCs upregulate PD1, b220, CD86, and IgM and downregulate CD27 and CD62L to become aaMBC. But it also seems likely that a fraction of aaMBCS expressing b220 and/or IgM may have a GC-independent development pathway. This hypothesis would be consistent with recent observations where $\operatorname{IgM}^{+}$aaMBC $\left(\operatorname{IgD}^{-} \mathrm{CD} 21^{-} \mathrm{CD} 27^{-}\right)$subsets appear to have two origins: a large fraction sharing mutation profiles similar to acMBCs (14), and a fraction with a clonal relationship similar to MZ-like B cells $(34,69)$. We propose that in a context of chronic malaria exposure, MZ-like B cells undergo GC-independent affinity maturation, by first upregulating b220 expression and then downregulating $\operatorname{IgD}, \mathrm{CD} 21$, and CD27 to generate early IgM short-lived MBC $(32,42)$. This hypothesis accounts, in part, for the lower frequency of MZ-like B cells observed with increasing exposure and explains the similar IgM expression on active and resting aMBC found in all exposure levels. Recently published work has shown that $P f$-specific $\operatorname{IgM}^{+}$MBCs have a precursor relationship with $\operatorname{IgM}^{+}$ASC, highlighting the importance of $\operatorname{IgM}^{+} \mathrm{B}$ cells as effective responders to malaria rechallenge (33).

Our study had some limitations that may influence the results. We previously studied this cohort of pregnant women and found no differences in the proportion of aMBC and circulating MZ-like $B$ cells between pregnant and non-pregnant malaria-exposed women (18). But pregnancy itself and sex could have had an effect on the expression of some markers between malaria-exposed pregnant women from PNG and non-exposed controls from Spain. We were incapable of providing non-exposed controls from PNG, as all women were somehow exposed to Plasmodium parasites; therefore exposure to other chronic infections in women from the Madang area could also have an effect. However, HIV prevalence is very low in the area. We were unable to provide absolute B cell counts, and frequencies were based on the total peripheral B cell population. Also, we analyzed total B cells and not Plasmodium-specific B cells, but recent work show good correlation with decreased AMA1-specific B cell frequencies and total B cells per milliliter of blood (69). Finally, the relatively small samples size may have had limited power to detect statistically significant differences between the low- and high-exposure groups.

We propose that malaria-associated expansion of active and resting aMBCs with increased expression of inhibitory PD1, CD95, and co-stimulatory CD80 in malaria-exposed women, coupled with increased CD71 and CD40 expression on aaMBCs, suggests that these cells are maintained in an anergic state (inhibitory profile) rather than going to apoptosis or cell death, helping to reduce the immune activation, and establishing a tolerogeniclike profile, as described on T cells $(56,70,71)$. The expression of these markers seems to play a key role in establishing immunehomeostatic mechanisms that inhibit chronically activated $\mathrm{B}$ cells while simultaneously maintaining high B cell frequencies. This mechanism would keep the B cell activation threshold high enough to control infection but impaired enough to tolerate it and prevent systemic inflammation. 
Plasmodium exposure decreased the frequencies of TACI expression and upregulated the frequencies of CD95 on circulating MZ-like B cells. TACI decreased frequency may result in a lack of capacity to generate long-lived antigen-specific IgG+ B cells, suggesting that increasing exposure leads to higher frequency of GC-independent MBC formation, favoring the rapid appearance of short-lived $\operatorname{IgM}^{+}$ASC. The upregulation of CD95, the increased frequencies of IgG and b220 suggest that MZ-like $\mathrm{B}$ cells are being activated. This marks the importance of MZ-like B cells as targets for antimalarial therapies and vaccine development. However, functional assays should be performed to try to shed light on the exact mechanisms and role of aaMBCs and MZ-like B cells on chronic infections.

\section{ETHICS STATEMENT}

Written informed consent was obtained from all study participants. This study was approved by the Medical Research Advisory Committee in PNG (MRAC 08.02) and by the Hospital Clinic of Barcelona Ethics Review Committee (Comitè Ètic d'Investigació Clínica), Spain.

\section{AUTHOR CONTRIBUTIONS}

IU performed the experiments, analyzed the data, and wrote the first draft of the manuscript. JC designed the flow cytometry panels and conceived the experimental design. PR obtained the preliminary data. $\mathrm{MO}, \mathrm{SH}$, and $\mathrm{CD}$ recruited and followed up volunteers. HR, PS, PR, GM, DB, and AJ processed lab samples. $\mathrm{DB}$ and $\mathrm{AJ}$ helped with performing the experiments. $\mathrm{AB}, \mathrm{IM}$, $\mathrm{CM}, \mathrm{SR}$, and $\mathrm{CD}$ contributed to the epidemiological study design and/or conduct. CD and GM supervised the experimental design and data analysis. JC, PR, GM, and CD interpreted the data. JC, PR, SR, GM, and CD participated in the writing up of the manuscript.

\section{REFERENCES}

1. Doi H, Tanoue S, Kaplan DE. Peripheral CD27-CD21- B-cells represent an exhausted lymphocyte population in hepatitis C cirrhosis. Clin Immunol (2014) 150:184-91. doi:10.1016/j.clim.2013.12.001

2. Moir S, Fauci AS. B-cell exhaustion in HIV infection: the role of immune activation. Curr Opin HIV AIDS (2014) 9:472-7. doi:10.1097/ coh.0000000000000092

3. Weiss GE, Crompton PD, Li S, Walsh LA, Moir S, Traore B, et al. Atypical memory B cells are greatly expanded in individuals living in a malaria-endemic area. J Immunol (2009) 183:2176-82. doi:10.4049/jimmunol.0901297

4. Sinton JA. Immunity or tolerance in malarial infections: (section of comparative medicine). Proc R Soc Med (1938) 31:1298-302.

5. Crompton PD, Moebius J, Portugal S, Waisberg M, Hart G, Garver LS, et al. Malaria immunity in man and mosquito: insights into unsolved mysteries of a deadly infectious disease. Annu Rev Immunol (2014) 32:157-87. doi:10.1146/ annurev-immunol-032713-120220

6. Portugal S, Pierce SK, Crompton PD. Young lives lost as B cells falter: what we are learning about antibody responses in malaria. JImmunol (2013) 190:3039-46. doi:10.4049/jimmunol.1203067

7. Galatas B, Bassat Q, Mayor A. Malaria parasites in the asymptomatic: looking for the hay in the haystack. Trends Parasitol (2016) 32:296-308. doi:10.1016/j. pt.2015.11.015

\section{ACKNOWLEDGMENTS}

The authors thank all the volunteers who consented to participate in this study; the PNG-Institute of Medical Research staff involved in the field, clinical and laboratory work: Regina Wangnapi, Alexandra Umbers, Leanne Robinson, Ushtana Antia, Danielle Stanisic, Anna Rosanas-Urgell, Celine Barnadas, Holger Unger, and Peter Siba; Pau Cisteró for contributing to the collection and processing of samples in Spain; The PregVax team, Mireia Piqueras, and Laura Puyol for logistics and administrative support. Peter Crompton and Gloria Patricia Gómez-Pérez for critical review of the manuscript.

\section{FUNDING}

This work was funded by the Instituto de Salud Carlos III (grant number PI14/01422), cofunded by FEDER funds/European Regional Development Fund (ERDF), the EU FP7 (PregVax, FP7/2007-2013 Grant 201588), the Ministerio de Economía y Competitividad (National R\&D Internationalization Program, EUROSALUD 2008, Grant EUS2009-03560), and the Malaria in Pregnancy Consortium through the Bill \& Melinda Gates Foundation (Grant 46099). GM was recipient of a Sara Borrell-ISCIII fellowship (CD010/00156). CD was supported by a fellowship from the Ministerio de Economía y Competitividad (Grant RYC-200802631) and was affiliate of the EU FP7 Network of Excellence EviMalaR. IU received funds from EviMalaR and the Agency for Management of University and Research Grants (AGAUR grant number 2014SGR991) for doctoral studies. ISGlobal is a member of the CERCA Programme, Generalitat de Catalunya.

\section{SUPPLEMENTARY MATERIAL}

The Supplementary Material for this article can be found online at http://journal.frontiersin.org/article/10.3389/fimmu.2017.00966/ full\#supplementary-material.

8. Schneider DS, Ayres JS. Two ways to survive infection: what resistance and tolerance can teach us about treating infectious diseases. Nat Rev Immunol (2008) 8:889-95. doi:10.1038/nri2432

9. Radbruch A, Muehlinghaus G, Luger EO, Inamine A, Smith KG, Dorner T, et al. Competence and competition: the challenge of becoming a long-lived plasma cell. Nat Rev Immunol (2006) 6:741-50. doi:10.1038/nri1886

10. Tarlinton D, Good-Jacobson K. Diversity among memory B cells: origin, consequences, and utility. Science (2013) 341:1205-11. doi:10.1126/science.1241146

11. Barrett L, Trehanpati N, Poonia S, Daigh L, Sarin SK, Masur H, et al. Hepatic compartmentalization of exhausted and regulatory cells in $\mathrm{HIV} / \mathrm{HCV}$ coinfected patients. J Viral Hepat (2015) 22:281-8. doi:10.1111/jvh.12291

12. Koncz G, Hueber AO. The Fas/CD95 receptor regulates the death of autoreactive B cells and the selection of antigen-specific B cells. Front Immunol (2012) 3:207. doi:10.3389/fimmu.2012.00207

13. Moir S, Malaspina A, Pickeral OK, Donoghue ET, Vasquez J, Miller NJ, et al. Decreased survival of B cells of HIV-viremic patients mediated by altered expression of receptors of the TNF superfamily. J Exp Med (2004) 200:587-99. doi:10.1084/jem.20032236

14. Portugal S, Tipton CM, Sohn H, Kone Y, Wang J, Li S, et al. Malaria-associated atypical memory B cells exhibit markedly reduced B cell receptor signaling and effector function. Elife (2015) 4. doi:10.7554/eLife.07218

15. Adlowitz DG, Barnard J, Biear JN, Cistrone C, Owen T, Wang W, et al. Expansion of activated peripheral blood memory B cells in rheumatoid 
arthritis, impact of B cell depletion therapy, and biomarkers of response. PLoS One (2015) 10:e0128269. doi:10.1371/journal.pone.0128269

16. Jacobi AM, Reiter K, Mackay M, Aranow C, Hiepe F, Radbruch A, et al. Activated memory B cell subsets correlate with disease activity in systemic lupus erythematosus: delineation by expression of CD27, IgD, and CD95. Arthritis Rheum (2008) 58:1762-73. doi:10.1002/art.23498

17. Charles ED, Brunetti C, Marukian S, Ritola KD, Talal AH, Marks K, et al. Clonal B cells in patients with hepatitis $\mathrm{C}$ virus-associated mixed cryoglobulinemia contain an expanded anergic CD21low B-cell subset. Blood (2011) 117:5425-37. doi:10.1182/blood-2010-10-312942

18. Requena P, Campo JJ, Umbers AJ, Ome M, Wangnapi R, Barrios D, et al. Pregnancy and malaria exposure are associated with changes in the B cell pool and in plasma eotaxin levels. J Immunol (2014) 193:2971-83. doi:10.4049/ jimmunol.1401037

19. Moir S, Ho J, Malaspina A, Wang W, DiPoto AC, O'Shea MA, et al. Evidence for HIV-associated B cell exhaustion in a dysfunctional memory B cell compartment in HIV-infected viremic individuals. J Exp Med (2008) 205:1797-805. doi:10.1084/jem.20072683

20. Asito AS, Moormann AM, Kiprotich C, Ng'ang’a ZW, Ploutz-Snyder R, Rochford R. Alterations on peripheral B cell subsets following an acute uncomplicated clinical malaria infection in children. Malar J (2008) 7:238. doi:10.1186/1475-2875-7-238

21. Weiss GE, Clark EH, Li S, Traore B, Kayentao K, Ongoiba A, et al. A positive correlation between atypical memory B cells and Plasmodium falciparum transmission intensity in cross-sectional studies in Peru and Mali. PLoS One (2011) 6:e15983. doi:10.1371/journal.pone.0015983

22. Hu Z, Luo Z, Wan Z, Wu H, Li W, Zhang T, et al. HIV-associated memory B cell perturbations. Vaccine (2015) 33:2524-9. doi:10.1016/j.vaccine.2015. 04.008

23. Portugal S, Moebius J, Skinner J, Doumbo S, Doumtabe D, Kone Y, et al. Exposure-dependent control of malaria-induced inflammation in children. PLoS Pathog (2014) 10:e1004079. doi:10.1371/journal.ppat.1004079

24. Ampomah P, Stevenson L, Ofori MF, Barfod L, Hviid L. B-cell responses to pregnancy-restricted and -unrestricted Plasmodium falciparum erythrocyte membrane protein 1 antigens in Ghanaian women naturally exposed to malaria parasites. Infect Immun (2014) 82:1860-71. doi:10.1128/IAI.01514-13

25. Illingworth J, Butler NS, Roetynck S, Mwacharo J, Pierce SK, Bejon P, et al. Chronic exposure to Plasmodium falciparum is associated with phenotypic evidence of B and T cell exhaustion. JImmunol (2013) 190:1038-47. doi:10.4049/jimmunol.1202438

26. Asito AS, Piriou E, Jura WG, Ouma C, Odada PS, Ogola S, et al. Suppression of circulating IgD+CD27+ memory B cells in infants living in a malaria-endemic region of Kenya. Malar J (2011) 10:362. doi:10.1186/1475-2875-10-362

27. Scholzen A, Sauerwein RW. How malaria modulates memory: activation and dysregulation of B cells in Plasmodium infection. Trends Parasitol (2013) 29:252-62. doi:10.1016/j.pt.2013.03.002

28. Sullivan RT, Kim CC, Fontana MF, Feeney ME, Jagannathan P, Boyle MJ, et al. FCRL5 delineates functionally impaired memory B cells associated with Plasmodium falciparum exposure. PLoS Pathog (2015) 11:e1004894. doi:10.1371/journal.ppat.1004894

29. Gomez-Perez GP, van Bruggen R, Grobusch MP, Dobano C. Plasmodium falciparum malaria and invasive bacterial co-infection in young African children: the dysfunctional spleen hypothesis. Malar J (2014) 13:335. doi:10.1186/1475-2875-13-335

30. Weill JC, Weller S, Reynaud CA. Human marginal zone B cells. Annu Rev Immunol (2009) 27:267-85. doi:10.1146/annurev.immunol.021908.132607

31. Cerutti A, Cols M, Puga I. Marginal zone B cells: virtues of innate-like antibody-producing lymphocytes. Nat Rev Immunol (2013) 13:118-32. doi:10.1038/nri3383

32. Taylor JJ, Pape KA, Jenkins MK. A germinal center-independent pathway generates unswitched memory B cells early in the primary response. J Exp Med (2012) 209:597-606. doi:10.1084/jem.20111696

33. Krishnamurty AT, Thouvenel CD, Portugal S, Keitany GJ, Kim KS, Holder A, et al. Somatically hypermutated Plasmodium-specific $\operatorname{IgM}(+)$ memory B cells are rapid, plastic, early responders upon malaria rechallenge. Immunity (2016) 45:402-14. doi:10.1016/j.immuni.2016.06.014

34. Bagnara D, Squillario M, Kipling D, Mora T, Walczak AM, Da Silva L, et al. A reassessment of IgM memory subsets in humans. J Immunol (2015) 195:3716-24. doi:10.4049/jimmunol.1500753
35. Requena $\mathrm{P}$, Arevalo-Herrera $\mathrm{M}$, Menegon $\mathrm{M}$, Martinez-Espinosa FE, Padilla N, Botto-Menezes C, et al. Naturally acquired binding-inhibitory antibodies to Plasmodium vivax Duffy binding protein in pregnant women are associated with higher birth weight in a multicenter study. Front Immunol (2017) 8:163. doi:10.3389/fimmu.2017.00163

36. Wong J, Hamel MJ, Drakeley CJ, Kariuki S, Shi YP, Lal AA, et al. Serological markers for monitoring historical changes in malaria transmission intensity in a highly endemic region of Western Kenya, 1994-2009. Malar J (2014) 13:451. doi:10.1186/1475-2875-13-451

37. Idris ZM, Chan CW, Mohammed M, Kalkoa M, Taleo G, Junker K, et al. Serological measures to assess the efficacy of malaria control programme on Ambae Island, Vanuatu. Parasit Vectors (2017) 10:204. doi:10.1186/ s13071-017-2139-z

38. Smith DL, Drakeley CJ, Chiyaka C, Hay SI. A quantitative analysis of transmission efficiency versus intensity for malaria. Nat Commun (2010) 1:108. doi:10.1038/ncomms1107

39. Dewasurendra RL, Dias JN, Sepulveda N, Gunawardena GSA, Chandrasekharan N, Drakeley C, et al. Effectiveness of a serological tool to predict malaria transmission intensity in an elimination setting. BMC Infect Dis (2017) 17:49. doi:10.1186/s12879-016-2164-0

40. Drakeley CJ, Corran PH, Coleman PG, Tongren JE, McDonald SLR, Carneiro I, et al. Estimating medium- and long-term trends in malaria transmission by using serological markers of malaria exposure. Proc Natl Acad Sci U S A (2005) 102:5108-13. doi:10.1073/pnas.0408725102

41. Benjamini Y, Hochberg Y. Controlling the false discovery rate: a practical and powerful approach to multiple testing. J R Stat Soc (1995) 57:289-300.

42. Sanz I, Wei C, Lee FE, Anolik J. Phenotypic and functional heterogeneity of human memory B cells. Semin Immunol (2008) 20:67-82. doi:10.1016/j. smim.2007.12.006

43. Ampomah P, Stevenson L, Ofori MF, Barfod L, Hviid L. Kinetics of B cell responses to Plasmodium falciparum erythrocyte membrane protein 1 in Ghanaian women naturally exposed to malaria parasites. J Immunol (2014) 192:5236-44. doi:10.4049/jimmunol.1400325

44. Suvas S, Singh V, Sahdev S, Vohra H, Agrewala JN. Distinct role of CD80 and CD86 in the regulation of the activation of B cell and B cell lymphoma. J Biol Chem (2002) 277:7766-75. doi:10.1074/jbc.M105902200

45. Deng R, Cassady K, Li X, Yao S, Zhang M, Racine J, et al. B7H1/CD80 interaction augments $\mathrm{PD}$-1-dependent $\mathrm{T}$ cell apoptosis and ameliorates graft-versushost disease. J Immunol (2015) 194:560-74. doi:10.4049/jimmunol.1402157

46. Guzman-Rojas L, Sims-Mourtada JC, Rangel R, Martinez-Valdez H. Life and death within germinal centres: a double-edged sword. Immunology (2002) 107:167-75. doi:10.1046/j.1365-2567.2002.01494.x

47. O’Donnell KA, Yu D, Zeller KI, Kim JW, Racke F, Thomas-Tikhonenko A, et al. Activation of transferrin receptor 1 by c-Myc enhances cellular proliferation and tumorigenesis. Mol Cell Biol (2006) 26:2373-86. doi:10.1128/ mcb.26.6.2373-2386.2006

48. Chitambar CR, Massey EJ, Seligman PA. Regulation of transferrin receptor expression on human leukemic cells during proliferation and induction of differentiation. Effects of gallium and dimethylsulfoxide. J Clin Invest (1983) 72:1314-25. doi:10.1172/jci111087

49. Daniels-Wells TR, Helguera G, Rodriguez JA, Leoh LS, Erb MA, Diamante G, et al. Insights into the mechanism of cell death induced by saporin delivered into cancer cells by an antibody fusion protein targeting the transferrin receptor 1. Toxicol In Vitro (2013) 27:220-31. doi:10.1016/j.tiv.2012.10.006

50. Fassl S, Leisser C, Huettenbrenner S, Maier S, Rosenberger G, Strasser S, et al. Transferrin ensures survival of ovarian carcinoma cells when apoptosis is induced by TNFalpha, FasL, TRAIL, or Myc. Oncogene (2003) 22:8343-55. doi:10.1038/sj.onc.1207047

51. Morrow M, Valentin A, Little R, Yarchoan R, Pavlakis GN. A splenic marginal zone-like peripheral blood CD27+B220- B cell population is preferentially depleted in HIV type 1-infected individuals. AIDS Res Hum Retroviruses (2008) 24:621-33. doi:10.1089/aid.2007.0186

52. Figgett WA, Fairfax K, Vincent FB, Le Page MA, Katik I, Deliyanti D, et al. The TACI receptor regulates T-cell-independent marginal zone B cell responses through innate activation-induced cell death. Immunity (2013) 39:573-83. doi:10.1016/j.immuni.2013.05.019

53. Park GB, Kim YS, Lee H-K, Cho D-H, Kim D, Hur DY. CD80 (B7.1) and CD86 (B7.2) induce EBV-transformed B cell apoptosis through the Fas/FasL pathway. Int J Oncol (2013) 43:1531-40. doi:10.3892/ijo.2013.2091 
54. Manjarrez-Orduno N, Quach TD, Sanz I. B cells and immunological tolerance. J Invest Dermatol (2009) 129:278-88. doi:10.1038/jid.2008.240

55. Zhang Y, Li J, Zhang YM, Zhang XM, Tao J. Effect of TACI signaling on humoral immunity and autoimmune diseases. JImmunol Res (2015) 2015:247426. doi:10.1155/2015/247426

56. Park J-J, Omiya R, Matsumura Y, Sakoda Y, Kuramasu A, Augustine MM, et al. B7-H1/CD80 interaction is required for the induction and maintenance of peripheral T-cell tolerance. Blood (2010) 116:1291-8. doi:10.1182/ blood-2010-01-265975

57. Zinocker S, Schindler CE, Skinner J, Rogosch T, Waisberg M, Schickel JN, et al. The $\mathrm{V}$ gene repertoires of classical and atypical memory B cells in malaria-susceptible West African children. JImmunol (2015) 194:929-39. doi:10.4049/jimmunol.1402168

58. Kaminski DA, Wei C, Qian Y, Rosenberg AF, Sanz I. Advances in human B cell phenotypic profiling. Front Immunol (2012) 3:302. doi:10.3389/ fimmu.2012.00302

59. Zander RA, Obeng-Adjei N, Guthmiller JJ, Kulu DI, Li J, Ongoiba A, et al. PD-1 co-inhibitory and OX40 co-stimulatory crosstalk regulates helper T cell differentiation and anti-Plasmodium humoral immunity. Cell Host Microbe (2015) 17:628-41. doi:10.1016/j.chom.2015.03.007

60. Weiss GE, Traore B, Kayentao K, Ongoiba A, Doumbo S, Doumtabe D, et al. The Plasmodium falciparum-specific human memory B cell compartment expands gradually with repeated malaria infections. PLoS Pathog (2010) 6:e1000912. doi:10.1371/journal.ppat.1000912

61. Salem ML, El-Badawy A. Programmed death-1/programmed death-L1 signaling pathway and its blockade in hepatitis $\mathrm{C}$ virus immunotherapy. World J Hepatol (2015) 7:2449-58. doi:10.4254/wjh.v7.i23.2449

62. Rodriguez-Bayona B, Ramos-Amaya A, Perez-Venegas JJ, Rodriguez C, Brieva JA. Decreased frequency and activated phenotype of blood CD27 IgD IgM B lymphocytes is a permanent abnormality in systemic lupus erythematosus patients. Arthritis Res Ther (2010) 12:R108. doi:10.1186/ ar3042

63. Metcalfe W, Anderson J, Trinh VA, Hwu WJ. Anti-programmed cell death-1 (PD-1) monoclonal antibodies in treating advanced melanoma. Discov Med (2015) 19:393-401.

64. Isnardi I, Ng Y-S, Menard L, Meyers G, Saadoun D, Srdanovic I, et al. Complement receptor 2/CD21- human naive B cells contain mostly autoreactive unresponsive clones. Blood (2010) 115:5026-36. doi:10.1182/ blood-2009-09-243071

65. Tsuji S, Cortesao C, Bram RJ, Platt JL, Cascalho M. TACI deficiency impairs sustained Blimp-1 expression in B cells decreasing long-lived plasma cells in the bone marrow. Blood (2011) 118:5832-9. doi:10.1182/blood-2011-05-353961

66. Wipasa J, Suphavilai C, Okell LC, Cook J, Corran PH, Thaikla K, et al. Long-lived antibody and B cell memory responses to the human malaria parasites, Plasmodium falciparum and Plasmodium vivax. PLoS Pathog (2010) 6:e1000770. doi:10.1371/journal.ppat.1000770

67. Langhorne J, Ndungu FM, Sponaas A-M, Marsh K. Immunity to malaria: more questions than answers. Nat Immunol (2008) 9:725-32. doi:10.1038/ni.f.205

68. Muellenbeck MF, Ueberheide B, Amulic B, Epp A, Fenyo D, Busse CE, et al. Atypical and classical memory B cells produce Plasmodium falciparum neutralizing antibodies. J Exp Med (2013) 210:389-99. doi:10.1084/jem.20121970

69. Frosch AE, Odumade OA, Taylor JJ, Ireland K, Ayodo G, Ondigo B, et al. Decrease in numbers of naive and resting B cells in HIV-infected Kenyan adults leads to a proportional increase in total and Plasmodium falciparum-specific atypical memory B cells. J Immunol (2017) 198(12):4629-38. doi:10.4049/ jimmunol.1600773

70. Nixon BG, Li MO. Satb1: restraining PD1 and T cell exhaustion. Immunity (2017) 46:3-5. doi:10.1016/j.immuni.2017.01.002

71. Wieland D, Kemming J, Schuch A, Emmerich F, Knolle P, NeumannHaefelin C, et al. TCF1+ hepatitis C virus-specific CD8+ T cells are maintained after cessation of chronic antigen stimulation. Nat Commun (2017) 8:15050. doi:10.1038/ncomms15050

Conflict of Interest Statement: The authors declare that the research was conducted in the absence of any commercial or financial relationships that could be construed as a potential conflict of interest.

Copyright () 2017 Ubillos, Campo, Requena, Ome-Kaius, Hanieh, Rose, Samol, Barrios, Jiménez, Bardají, Mueller, Menéndez, Rogerson, Moncunill and Dobaño. This is an open-access article distributed under the terms of the Creative Commons Attribution License (CC BY). The use, distribution or reproduction in other forums is permitted, provided the original author(s) or licensor are credited and that the original publication in this journal is cited, in accordance with accepted academic practice. No use, distribution or reproduction is permitted which does not comply with these terms. 